\title{
A study of socio-demographic variables of patients admitted with dissociative symptoms in a tertiary care hospital
}

\author{
Datta $\mathrm{A}^{1}$, Bhagabati $\mathrm{D}^{2}$, Bera $\mathrm{NK}^{3}$, Kalita $\mathrm{N}^{4}$
}

${ }^{1}$ Medical Officer, Department of Psychiatry, North Bengal Medical College, ${ }^{2}$ Professor and Head, Department of Psychiatry, Gauhati Medical College, ${ }^{3}$ Professor and Head, Department of Psychiatry, North Bengal Medical College, ${ }^{4}$ Consultant Psychiatrist, Bongaigaon, Assam

\section{ABSTRACT}

Aims : To study the socio-demographic variables of the patients who were admitted in the department of psychiatry with an initial diagnosis of dissociative disorder.

Methods : Patients who were initially admitted with a diagnosis of dissociative symptoms were taken into the study sample and the various sociodemographic variables such as age, sex, religion, educational status, marital status were studied. ICD-10 diagnostic criteria for dissociative disorders was used to diagnose dissociative disorders. The patients who were not initially diagnosed with dissociative disorders were excluded from the study.

Results : The results show that most of the patients $(n=38)$ were young female $(84.21 \%)$ patients belonging to $10-20$ year age group (39.47\%),currently married (44.26\%),educated ( $84.21 \%)$ and Hindu by religion ( $84.21 \%)$.In the majority of the patients the initial diagnosis at the time of admission was not changed at the time of discharge $(84.21 \%)$.

Conclusion : The findings of the study concur with the findings of other studies that dissociative disorders is more common in females of the 10-30 year age group and that the initial diagnosis remained unchanged in the majority of the patients. Most of the patients were educated though the level of education was not very high. The prognosis was good in the majority of the patients.

\section{INTRODUCTION}

According to DSM IV TR criteria "the essential features of dissociative disorder is a disruption of consciousness, memory, identity or perception of the environment the disturbance may be sudden or gradual, transient or chronic"1. Janet provided the first theoretical account of dissociation in his detailed description of hysteria in the nineteenth

\section{Corresponding Author :}

Dr Nirmal Kumar Bera, Professor and Head, Dept of Psychiatry, North Bengal Medical College, Sushrutnagar, Darjeeling - 734012

Email id : drbera@yahoo.co.in century and is generally regarded as the founder of modern approaches to dissociation and dissociative disorders ${ }^{1}$. The term dissociative disorders is almost unique in descriptive psychopathology because the term itself identifies the hypothetical processes that underlie the disorder ${ }^{2}$. The popular media has been fascinated by the various forms of dissociation especially multiple personality disorder best exemplified by RL Stevenson's 'The strange case of Dr Jekyll and Mr. Hyde'. In this study the authors have tried to study the socio-demographic variables of the patients who were admitted in the department of psychiatry, Gauhati Medical College and North Bengal Medical College with an initial diagnosis of dissociative disorder. 
A Study of Socio-demographic variables of patients admitted with dissociative symptoms in a tertiary care hospital

\section{METHOD}

We studied the patients that had been admitted in the departments of psychiatry Gauhati Medical College from 01-01-2011 to 31-12-2011 and North Bengal Medical College from 01-12-2014 to 31-072015 that were initially provisionally diagnosed as dissociative disorder. The various tools used included were the case information sheet from the inpatient department which was recovered from the medical records department of the hospital. Patients who were not initially diagnosed with dissociative disorder were excluded from the study sample. Also, patients with any significant medical or surgical condition were excluded from the study. Diagnostic criteria as specified in the ICD-10 Classification of Mental and Behavioural disorders were used to diagnose dissociative disorders.

\section{RESULTS}

The various socio demographic parameters of the various patients were studied and the following analysis of the data was made :

Age: Most of the patients belonged to the 10-20 yr old age group. The youngest patient in the study sample was 13 years old and the oldest patient was 60 years old. The mean age of the patients is 23.05 years. The bar diagram-1 below is a graphical representation of the age distribution of the patients.

Diagram - 1 :

Graphical Representation of the age Distribution of the Patients.

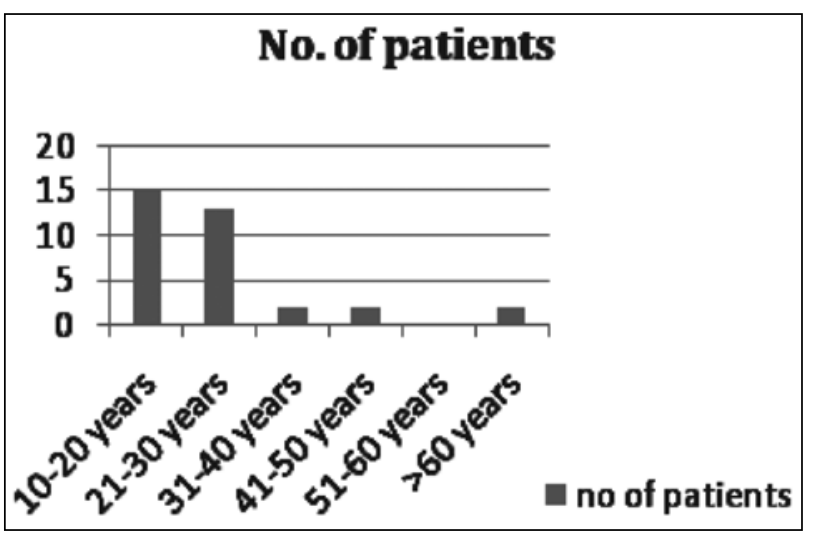

Sex : Among the 38 patients in the study sample, $32(84.21 \%)$ were female. Males accounted for 6 of $38(15.79 \%)$

Religion : 26 of the patients $(84.21 \%)$ were Hindu by religion and the other $12(15.78 \%)$ patients were Muslim by religion. No patient of any other religion was found in the study sample.

Marital Status : $17(44.36 \%)$ patients were currently married. ${ }^{1}(2.63 \%)$ patient was a widow. 20 (52.63\%) other patients were unmarried.

Education Status : The majority of patients were educated $(n=32 / 38,84.21 \%)$ but most of them did not pass class $\mathrm{X}$ or matriculation examination $(n=26 / 32,81.25 \%)$.

Duration of Hospital Stay : The duration of hospital stay ranged from 1 day to 17 days. The mean duration of hospital stay was 9.47 days.

Past History of Similar Episodes in the Past : 10 patients $(26.32 \%)$ had similar illness in the past whereas the $28(73.68 \%)$ remaining patients had dissociative symptoms.

\section{PSYCHOTHERAPY AND COUNSELING :}

Psychotherapy and counseling was done in some form in $16(42.10 \%)$ of the patients whereas $22(57.89 \%)$ of the patients did not receive any psychotherapy and were treated solely on medications.
Diagram - 2 :
Graphical Representation of Psychotherapy Treatment History

\section{Psychotherapy given in any form}

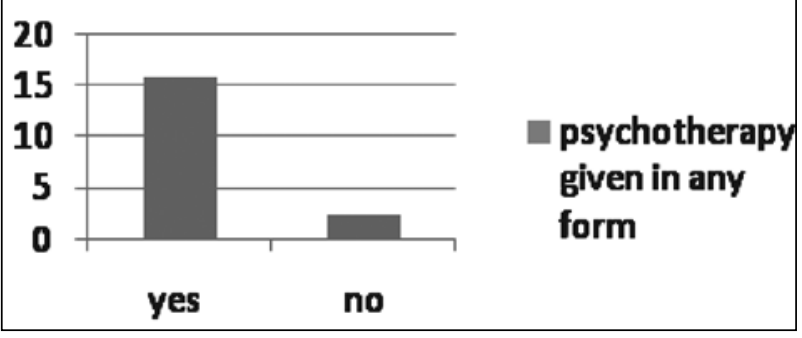


A Study of Socio-demographic variables of patients admitted with dissociative symptoms in a tertiary care hospital

Stress Factor : A definite stress factor was found out in $28(73.768 \%)$ of the patients whereas the remaining $10(26.31 \%)$ did not have any obvious stressor (elicited) which precipitated the illness. 21 (55.63\%) of the patients were from rural areas whereas 17 $(44.73 \%)$ were from urban area.A definite stress factor was found in almost 20 patients (52.63\%) from urban areas.

\section{Diagram - 3 :}

Graphical representation of stress factor

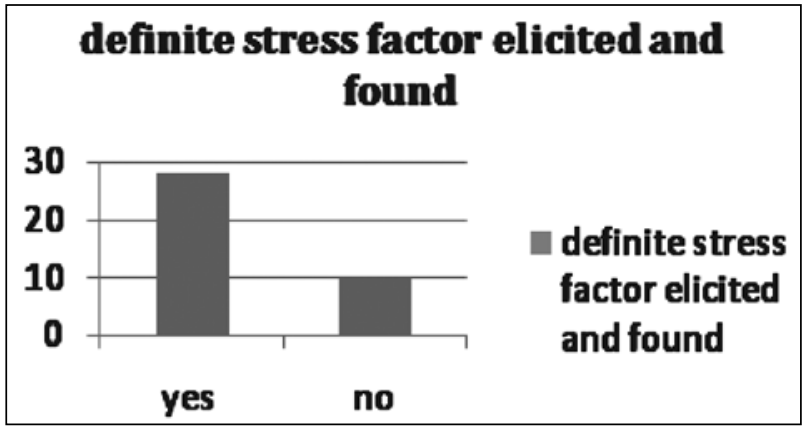

Final Diagnosis : All patients were initially provisionally diagnosed as suffe-ring from dissociative disorder when they either presented in the casualty department or the out-patient department of Gauhati Medical College and North Bengal Medical College. At the time of discharge there were 6 patients in whom the diagnosis was changed. 2 patients each were finally diagnosed with Acute and Transient Psychosis and Acute Stress Reaction. One patient was diagnosed with helminthiasis and appendicitis. Another patient was diagnosed with somatoform disorder. All other patients were diagnosed with dissociative disorder at the time of discharge.
Diagram - 4 :

Graphical Representation of Final Diagnosis

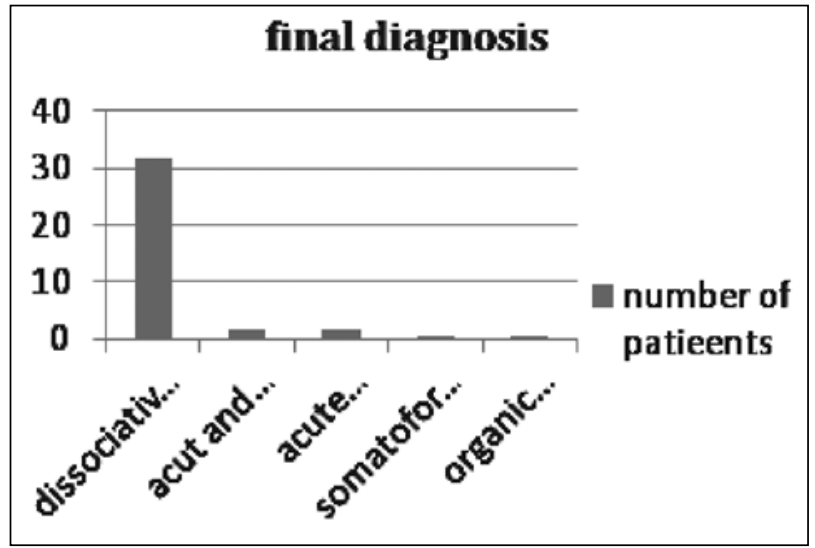

Liason with Other Departments : 13 patients required consultations from other departments during their stay in the hospital. One patient required consultations from Neurology, Medicine and ENT department whereas another required consultation from Dermatology department and The Department of TB \& Chest. Other than these two patients three patients each required consultation each from Medicine and Neurology departments whereas 2 required ENT consultation. One patient each required Surgical, Ophthalmological and Obstetrics and gynaecology consultation.

Diagram-5 :

Graphical Representation of Liason with Other Departments

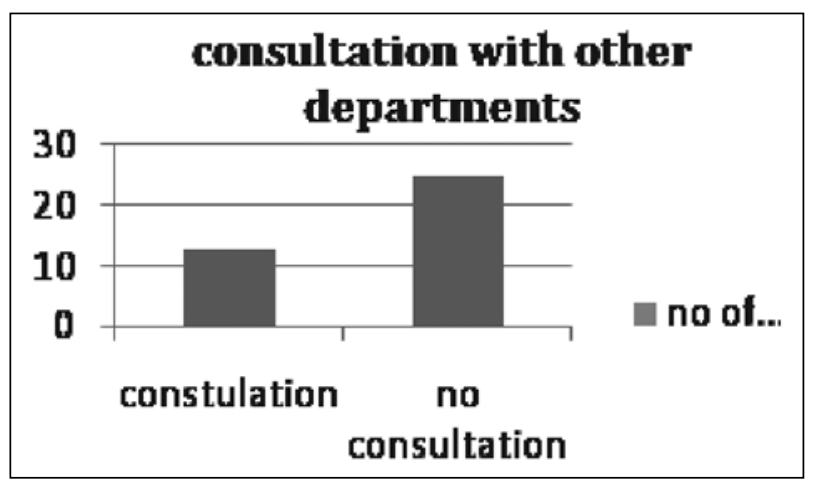

Discharge : Thirty four patients were discharged after they improved on medication. Four of the patients were discharged against medical advice within the first 2-4 days of admission. 


\section{A Study of Socio-demographic variables of patients admitted with dissociative symptoms in a tertiary care hospital}

Other Findings : We found that motor findings $(n=22,57.9 \%)$ were the most common presentation followed by paresis ( $\mathrm{n}=8,21.05 \%)$, mixed $(\mathrm{n}=6,15.79 \%)$ and aphonia $(\mathrm{n}=2,5.26 \%)$. Among motor findings the most common was pseudoseizures $(n=12 / 22,54.45 \%)$.

\section{DISCUSSION}

In our study the incidence of dissociative disorders is more in females that males and the majority of the patients belonged to the $10-20$ and 21-30 year age groups which corresponds to studies by Vyas et $\mathrm{al}^{3}$, Bagadia et $\mathrm{al}^{4}$, and Choudhury et $\mathrm{al}^{4}$. A study from UAE by Bener et al found that $59.4 \%$ of all admissions who were diagnosed with dissociative disorders were females ${ }^{7}$. Another study done in NIMHANS, Bangalore by Prabhuswamy et $\mathrm{al}^{6}$ found that most in patients who were diagnosed with dissociative disorders had a good prognosis which correlates with the findings of our study. Early diagnosis and treatment correlated with a better prognosis. Most of the findings of this study support the findings of an earlier study from the region ${ }^{8}$. Most of the patients who were admitted to our department hailed from the Kamrup regions of the state of Assam which may be attributed to the fact that the Hospital is situated in the same area and there is better accessibility for patients of the above mentioned area.

\section{CONCLUSIONS}

The findings of the study indicate that dissociative disorders are more common in young females, Hindu by religion, who are married and most of whom were educated with was present in most of the patients. Most of the patients who were admitted with the initial diagnosis of dissociative disorder the diagnosis was not changed at the time of discharge. The majority of the patients were educated $(84.21 \%)$ though the level of education was not very high.

\section{LIMITATIONS}

The sample size was small. As this was a crosssectional study, the pattern of symptomatology in subsequent recurrence could not be studied thereof. Another limitation of the study is that the sample study studies only the in-patient population and so the sample may not be representative of the local population.

\section{REFERENCES}

1. Saddock BJ, Saddock VA,Ruiz P.A comprehensive textbook of Psychiatry. 9th ed. Piladelphia, USA. Lippincott Williama and Wilkins. 2009

2. Kihlstrom JF, Glisky ML, Anguilo MJ. Dissociative Tendencies and Dissociative Disorders. J Am Psychol. 1994; 103(1) : 117-124

3. Vyas JN, Bharadwaj PK. A study of hysteria - an analysis of 304 patients. Indian J Psychiatry. 1977; 19: 71-4

4. Bagadia VN, Shastri PC, Shah JP. Hysteria : A study of demographic factors. Indian J Psychiatry. 1973; 5 : 179.

5. Choudhury S, Bhatia MS, Mallick SC. Hysteria in female hospitall: Paper presented at 48th Annual National conference of Indian Psychiatric Society. 1996. p. 3225.

6. Prabhuswamy M, Jairam R, Srinath S, Grimaji S, Seshadri SP. A Syatematic Chart Reveiw of Inpatient Population with childhood dissociative disorders. J Ind Assoc. Child Adolesc. Mental Health. 2006; 2(3) : 72-3.

7. Bener A, Saad AG, Micallef R, Ghuloum S, Sabri S. Sociodemographic and Clinical correlates of patients with Dissociative Disorders in an Arabian Society. Med Princ Pract. 2006; 15 : 362-63.

8. Deka K, Chaudhuri PK, Bora K, Kalita PA. A study of the clinical correlates and socio-demograaphic profile in conversion disorders. Indian JPsychiatry. 2007: 49(3), 205-7. 